\title{
Central Autonomic Network Disturbance in Myalgic Encephalomyelitis/Chronic Fatigue Syndrome: A Pilot Study
}

\author{
Mark A. Zinn*, Marcie L. Zinn, and Leonard A. Jason \\ DePaul University, Center for Community Research, Chicago, Illinois, USA
}

\begin{abstract}
Myalgic encephalomyelitis/chronic fatigue syndrome (ME/CFS) is a debilitating disease of the central nervous system known to be associated with multiple behavioral symptoms (fatigue, low stamina, dizziness, etc.) combined with autonomic nervous system (ANS) dysfunction, thus implicating the central autonomic network (CAN). Postexertional malaise (PEM) is a core feature of ME/CFS, characterized by a pathological reduction in stamina in response to performing minor physical or mental tasks, often lasting at least 24 hours. Exact lowresolution electromagnetic tomography (eLORETA) allows noninvasive investigation of cortical regions of interest that may contribute to better understanding of the role of the brain disturbances in behavioral manifestations of PEM. This pilot study therefore aimed to use eLORETA to characterize changes in current density in cortical structures related to the CAN following submaximal isometric handgrip exercise in seven patients with ME/CFS and six neurotypical healthy controls (HCs). Resting EEG was recorded at pre- and posthandgrip, and 24 hours later. Findings showed that significant differences occurred immediately posttest, which were most pronounced after 24 hours, particularly in the low alpha $(8-10 \mathrm{~Hz})$ and low beta $(13-18 \mathrm{~Hz})$ frequency subbands. Together, the present findings offer support for EEG source localization techniques to investigate PEM. If confirmed, this study could provide a useful instrument for aiding functional diagnosis and evaluation of treatment outcomes.
\end{abstract}

Keywords: chronic fatigue syndrome; myalgic encephalomyelitis; central autonomic network; handgrip; postexertional malaise; eLORETA; central fatigue

Citation: Zinn, M. A., Zinn, M. L., \& Jason, L. A. (2021). Central autonomic network disturbance in myalgic encephalomyelitis/chronic fatigue syndrome: A pilot study. NeuroRegulation, 8(2), 73-86. https://doi.org/10.15540/nr.8.2.73

*Address correspondence to: Mark A. Zinn, DePaul University, Center for Community Research, 990 W. Fullerton Ave., Chicago, IL 60614, USA. Email: mzinn@depaul.edu

Copyright: (c) 2021. Zinn et al. This is an Open Access article distributed under the terms of the Creative Commons Attribution License (CC-BY).

\section{Edited by:}

Rex L. Cannon, PhD, SPESA Research Institute, Knoxville, Tennessee, USA

\section{Reviewed by:}

Randall Lyle, PhD, Mount Mercy University, Cedar Rapids, lowa, USA

Tonya Morosoli, MSc, Clínica de Neuropsicología Diagnóstica y Terapéutica, Mexico City, Mexico; ECPE, Harvard T. H. Chan School of Public Health, Boston, Massachusetts, USA

\section{Introduction}

Myalgic encephalomyelitis/chronic fatigue syndrome (ME/CFS) is a complex disease of the central nervous system (Bansal et al., 2012; Loebel et al., 2014; Underhill, 2015) associated with neuroinflammation (Barah et al., 2014; Maes et al., 2012; Nakatomi et al., 2014, 2014; VanElzakker et al., 2018), autonomic dysfunction (Barnden et al., 2016), cellular hypometabolic problems (Naviaux et al., 2016), and progressive brain deterioration (Chen et al., 2008; Shan et al., 2016). Most cases of $\mathrm{ME} / \mathrm{CFS}$ are precipitated by an acute viral infection
(Rasa et al., 2018; Roos \& Miravalle, 2014) or less commonly from traumatic brain injury (accident or other head trauma), endogenous brain injury (i.e., stroke, tumor, etc.), or chemical/toxin exposure (Cho et al., 2006). Signs and symptoms suggest a brain infection involving flu-like symptoms such as acute fever, headache, tender lymph nodes, sore throat, neurologic deficits, and altered mental status (i.e., impaired consciousness; Scheld et al., 2014). Recent studies have demonstrated a need for understanding the effects of physical activity on neurological processes in ME/CFS, specifically the central autonomic network (CAN) that controls the 
peripheral autonomic nervous system (ANS) (Barnden et al., 2016; Beaumont et al., 2012; Bozzini et al., 2018; Cambras et al., 2018; Cvejic et al., 2017; Orjatsalo et al., 2018; Roerink et al., 2018; Van Cauwenbergh et al., 2014).

The cause of ME/CFS is unknown, as is the case with many known neurological diseases (Holgate et al., 2011), and patients with neurological disorders typically have a clinical presentation with complaints of severe, unrelenting central fatigue (Chaudhuri \& Behan, 2004), depending on the nature and extent of central involvement. Central fatigue in neurological disorders is linked to cognitive impairments such as reduced perceptual awareness, attention problems, memory impairments, reduced reasoning ability (Gunzelmann et al., 2019), and sleep inversion (Pajediene et al., 2018). Accordingly, the infectionfatigue causal relationships for ME/CFS have been reported as a primary source of central fatigue (Cook et al., 2012; Togo \& Natelson, 2013), which is known to be pervasive and multifactorial (Berelowitz et al., 1995; Zinn et al., 2018).

Numerous clinical conditions include fatigue as part of their etiology (Ropper \& Samuels, 2009) and the symptom sequelae of postexertional malaise (PEM) are widely recognized as the most debilitating and unrelenting feature of ME/CFS (Carruthers et al., 2011). PEM refers to debilitating loss of stamina accompanied by symptom flareups following minor physical or mental activity, lasting 24 hours or more (Carruthers et al., 2003; Stevens et al., 2018). All patients suffer in some manner from PEM which interferes with their baseline level of function (Carruthers et al., 2003) and at least 25\% of patients with ME/CFS are housebound or bedbound (Institute of Medicine, 2015; Pendergrast et al., 2016). PEM impacts the quality of life of sufferers and makes the disease particularly difficult to manage due to unpredictable variation in symptom frequency and severity (LaManca et al., 1998). Although mental activity is known to trigger PEM, it has been found to have close concordance with physical activity (Light et al., 2009, 2012). Studies using maximal cardiopulmonary exercise tests have found lower peak oxygen uptake $\left(\mathrm{VO}_{2} \max\right.$ ) in patients (Nijs et al., 2010; Ohashi et al., 2002; Snell et al., 2013; Stevens et al., 2018; Vanness et al., 2007; Vermeulen \& Vermeulen van Eck, 2014; Yoshiuchi et al., 2007), showing lower aerobic capacity possibly due to insufficient metabolic adaptation to incremental exercise (Shungu et al., 2012). However, it has been reported that severe cases are unable to endure maximal exercise tests (Stevens et al., 2018). Submaximal exercise tests have been utilized, but their results are not necessarily comparable to maximal tests (Meeus et al., 2007; Nijs et al., 2010). Consequently, there is a need to investigate PEM using an alternative approach with a lower response cost.

Fatigue is one of the primary covariates of autonomic disorders (Oosterwijck et al., 2017), making the ANS a principal target of research and clinical applications (Tanaka et al., 2015). The ANS largely depends on the integrity of global CNS states for regulating behavioral states and the rapid allocation of neuronal resources (Pfaff et al., 2008). The ANS, in coordination with the neuroendocrine system, regulates the cascading physiological events which serve as primary mediators of stress and arousal (McEwen et al., 2015). Operating synergistically with the CNS, the ANS promotes physiological stability through adaptive response to ever-changing internal and external demands (Benarroch, 2012; McEwen et al., 2015; Porges, 1992, 2009). However, a compromised ANS may disrupt CNS function altogether (Cleare, 2004; Sclocco et al., 2016), resulting in negative effects on cognitive function due to orthostatic intolerance, dyspnea, paresthesia, nausea, ataxia, cardiopulmonary irregularities, and thermal dysregulation (Mathias \& Bannister, 2013; Sandroni, 2012; Shan et al., 2016).

The CAN is a set of interconnected regions involved in top-down homeostatic control (Benarroch, 2012; Mo et al., 2019) of the peripheral ANS in coordination with intricate neuroimmune responses (Benarroch, 2019; Morrison \& Nakamura, 2019) and arousal responses (Saper, 2002), emphasizing its potential importance in ANS-related disease. The structures of the CAN were recently confirmed in a comprehensive meta-analysis of 43 task-based studies using the activation likelihood estimation (Turkeltaub et al., 2002), a widely used technique for showing the convergence of activated brain areas across different experiments. Many cortical regions were reportedly involved in cognitive, affective, and sensorimotor tasks for initiating autonomic outflow with neuroendocrine responses of the hypothalamus and 1) upper brainstem nuclei which regulate pain modulation and stress responses, 2) lower brainstem nuclei which control circulation, respiration, and Gl function, and 3) spinal level reflex centers (Benarroch, 1993, 2012).

The present study examined the cortical regions of the CAN using exact low-resolution electromagnetic tomography (eLORETA), an inverse solution that 
estimates cortical current density from EEG signals recorded at the scalp (Grech et al., 2008; PascualMarqui et al., 2011). Previous iterations of LORETA and eLORETA have been extensively used for source localization of brain activity in clinical populations (Babiloni et al., 2010; Canuet et al., 2012; Cao \& Slobounov, 2010; Caso et al., 2012; Clemens et al., 2008, 2010; Gianotti et al., 2007; Lantz et al., 1997; Lubar et al., 2003; Nishida et al., 2011; Toth et al., 2009). In a previous study, we used eLORETA to evaluate 50 patients with ME/CFS and 50 healthy controls (Zinn et al., 2018); patients were found to have generalized delta band $(1-3 \mathrm{~Hz})$ current density in $50 \%$ of the frontal lobe, bilaterally, including the anterior cingulate, insula, superior/inferior frontal gyrus, and ventromedial frontal gyrus. Focal delta activity in the left inferior frontal gyrus was associated with self-reported levels of reduced motivation from fatigue. The patients also demonstrated a reduction in beta-2 (19-21 Hz) current density in the somatomotor cortex, precuneus, and posterior cingulate. Together, these brain regions that were associated with central fatigue are also involved in central autonomic processing, thus implicating the $\mathrm{CAN}$ as a prime target for further investigation.

The main objective of this pilot study was to quantify the effects of physical exertion on CAN function in ME/CFS using an isometric handgrip task. Handgrip tasks are commonly used in stress literature to perturb the ANS (Nielsen \& Mather, 2015) and for the assessment of physiological function in clinical populations, such as mitochondrial disorders (Meulemans et al., 2007) and functional status of cancer patients (Norman et al., 2010). In patients with ME/CFS, handgrip studies have found increased heart rate and blood pressure, higher levels of norepinephrine (Wyller et al., 2009) as well as slowed motor speed (Ickmans et al., 2014), and associations with fatigue (Neu et al., 2014; Siemionow et al., 2004; Staud et al., 2015), maximal oxygen uptake (Jammes et al., 2020), and disease severity (Nacul et al., 2018).

Resting-state qEEG data were collected from all participants during 3 separate time points: 1 ) before handgrip, 2) immediately after handgrip, and 3) 24 hours later. Thus, the discrepancy between CAN function at pre vs. posthandgrip exercise was used to quantify PEM. It was hypothesized that patients with ME/CFS would differ significantly from the neurological healthy control $(\mathrm{HC})$ group at Time 1 (baseline). Next, due to the effects of PEM, it was predicted that differences between groups would increase at time 2 (immediately after the handgrip task) compared to baseline. Finally, differences between groups were predicted to be greater at time 3 (24 hours) due to the adverse effects of PEM in patients and return to baseline in HCs.

\section{Method}

\section{Participants}

This study was approved by the DePaul University Institutional Review Board in Chicago, Illinois (protocol \#MA119118PSY) and informed consent was obtained from all study participants after reading a written explanation of the experiment. There was no compensation for their involvement. Seven patients diagnosed with ME/CFS (4 female and 3 male, mean age: 54.29 years, \pm 17.52 ) and six healthy individuals ( 2 female and 4 male, mean age: $30.51, \pm 5.65)$ were enrolled in this study. Participants in this study were recruited from the Chicago, IL, metropolitan area from waitlists of past research studies and email communications. All patients met inclusion criteria specified by Fukuda et al. (1994) and Carruthers et al. (2003) with a physician diagnosis of ME/CFS. Exclusion criteria ruled out those with a history of a neurological disorder such as epilepsy or traumatic brain injury, presence of psychiatric disorders such as anxiety or depression, and other comorbidities. None of the participants were taking medications known to affect the EEG.

\section{Design}

This study utilized a mixed-model quasiexperimental design with repeated measures. The EEG data were collected at the Center for Community Research at DePaul University. For the period between the second recording on day 1 (posthandgrip) and the third recording on day 2 (24 hours later), all participants were instructed to avoid performing any laborious tasks such as lifting, housecleaning, grocery shopping, or any other strenuous physical tasks.

Prior to study visit, all participants completed an online version of the DePaul Symptom Questionnaire (DSQ; Jason et al., 2010) and the Short Form Medical Outcomes Survey (SF-36; Ware \& Sherbourne, 1992). Data for both questionnaires were collected and managed using the Research Electronic Data Capture (REDCap) hosted at DePaul University (Harris et al., 2009). The DSQ has good test-retest reliability above 0.70 and testretest correlations for symptom categories (Jason et al., 2015). The total score was calculated using the DSQ items regarding PEM. 
The SF-36 has been widely used in studies for the assessment of health status (Ware et al., 1993). It has shown high internal consistency and test-retest reliability estimates and discriminant validity among subscales (Ware et al., 1995). Questions are scored from 0 to 100 with lower scores indicating greater disability. Items $23,27,29$, and 31 from the vitality subscale were used to calculate the energy/fatigue scores.

\section{Handgrip Protocol}

Each participant performed an isometric handgrip task based on a protocol taken from (Jeppesen et al., 2007) using an adjustable handgrip strengthener (Kootek, Inc.). Before performing this task, grip strength was calibrated to $50 \%$ of the average maximal voluntary contraction force taken from three synchronized maximal voluntary contractions using the dominant hand. While performing the protocol, the participants were seated upright in a padded office chair while resting their elbow flexed at a $90^{\circ}$ angle on the armrest of the chair. After a 2-min break, the protocol was initiated whereby participants made repetitive submaximal grip force contractions in this manner for $3 \mathrm{~min}$ (18 total contractions). They were instructed to squeeze the handgrip for $5 \mathrm{~s}$, then relax for $5 \mathrm{~s}$ while watching a PowerPoint presentation (Microsoft, version 2010) with timed slides serving as cues for when to squeeze/relax. For each contraction, participants were instructed to fully squeeze the handgrip to achieve equal intensity levels throughout the task. They were encouraged to complete the task or continue until they could go no further. However, each participant was able to complete the task, and afterward, intensity ratings on a 1-10 visual analog scale were reported to be in the moderate range.

\section{EEG Recording}

Each EEG recording lasted for 5 min, during which participants were instructed to sit quietly while keeping their eyelids closed gently. The eyes-closed condition was chosen to minimize ocular artifact and maintain internal consistency with previous resting EEG studies. Participants were seated in a padded office chair and the examination room was well-lit. International 10/20 system electrode placement was achieved using an electrode cap system (ElectroCap International, Eaton, $\mathrm{OH}$ ) with a linked-ears reference. Impedances were checked and adjusted until all electrodes were below $5 \mathrm{k} \Omega$. EEG signals were acquired at $256 \mathrm{~Hz}$ sample frequency using a BrainMaster Discovery amplifier (BrainMaster Technologies, Bedford, $\mathrm{OH}$ ) to record 19 channels simultaneously from the following electrode locations: Fp1, Fp2, F3, F4, F7, F8, Fz, C3, C4, Cz,
P3, P4, Pz, T3, T4, T5, T6, O1, and O2. Before their first EEG recording, participants were briefly trained to minimize ocular and muscle artifacts. During training, they were asked to observe changes in the raw signal while blinking their eyes frequently and after tensing their facial muscles. After training, participants were subsequently asked to refrain from blinking as much as possible, and to relax their jaw and forehead muscles to the best of their ability. NeuroGuide software version 3.0.4 (Applied Neuroscience, Inc., Largo, FL) was used for recording and off-line processing. Eye-blink, muscle, and drowsiness artifacts were identified and eliminated using NeuroGuide's automated $z$-score artifact rejection algorithm set to high sensitivity, followed by visual inspection and manual editing by the technician. The remaining EEG epochs maintained greater than 95\% split-half and greater than $90 \%$ test-retest reliability coefficients as computed by NeuroGuide with at least 1.5 total minutes of artifact-free data remaining for analysis. Each participant record was then filtered offline between 1 and $30 \mathrm{~Hz}$ and exported into separate text files containing 2-s segments using a 75\% overlapping taper window (Kaiser \& Sterman, 2000).

\section{Source Localization}

LORETA-KEY software was used to estimate eLORETA for the intracortical distribution of electrical sources generated from scalp-recorded activity in a solution space of 6,239 voxels at $5 \mathrm{~mm}^{3}$ resolution and restricted to unambiguous cortical gray matter (Lancaster et al., 2000). Using a realistic head model (Fuchs et al., 2002), computations are mapped onto orthogonal brain slices of the MNI 152 standard template (Mazziotta et al., 2001) using standardized Montreal Neurological Institute (MNI) voxel coordinates in millimeters with neuroanatomical labels established by von Brodmann in 1909 referred to as Brodmann areas, which are based on corrected Talairach space (Brett et al., 2002). The latest iteration in a series of wellestablished tomography methods, including sLORETA (Pascual-Marqui, 2002) and LORETA (Pascual-Marqui et al., 1994), eLORETA has been validated in studies using combined magnetic resonance imaging (Mulert et al., 2004; Vitacco et al., 2002), and Positron Emission Tomography (Dierks et al., 2000; Pizzagalli et al., 2004; Zumsteg et al., 2005) and source findings obtained from implanted depth electrodes (Zumsteg et al., 2006a, 2006b). Furthermore, eLORETA has been validated for resting-state investigations based on 19 channels (Miraglia et al., 2021), a montage configuration found in many clinical studies (Aoki et al., 2019; Hata et al., 2016; Pascarelli et al., 2020; Vanneste \& 
De Ridder, 2013). A detailed description of this inverse method and its exact zero-error localization property are described in Pascual-Marqui et al. (2011). The LORETA-KEY software package for eLORETA/sLORETA is freely provided by the Key Institute for Brain-Mind Research, University Hospital of Psychiatry, Zurich at http://www.uzh.ch /keyinst/loreta.

Software utilities for eLORETA were used to define each cortical region of interest of the CAN a priori, using $\mathrm{MNI}$ coordinates reported in Beissner et al. (2013), and the single nearest voxel method was chosen to assign each region of interest to a single voxel with closest proximity to the coordinate entered. The voxel coordinates and regions of interest of the CAN used in this study included the anterior, middle, and posterior cingulate, ventromedial prefrontal gyri, anterior and posterior insula, supramarginal gyri, inferior parietal lobe, and other structures located within the parahippocampal gyri (e.g., amygdalae and hippocampi). The thalamus, red nucleus, and cerebellum regions were not included, given the subcortical limitations of eLORETA. Current density estimates within each CAN region of interest were then extracted for each of the following frequency bands: Delta $(1-3 \mathrm{~Hz})$, Theta $(4-7 \mathrm{~Hz})$, Alpha-1 (8-10 Hz), Alpha-2 (10-12 $\mathrm{Hz})$, Beta-1 $(13-18 \mathrm{~Hz})$, Beta-2 $(19-21 \mathrm{~Hz})$, and
Beta-3 $(22-30 \mathrm{~Hz})$. To eliminate variability in spectral power and lower error variance, subjectwise normalization was performed, where the total activity over all voxels and frequencies was computed, giving a single number, used as divisor for scaling the data. Statistical analyses of the eLORETA data were performed using SPSS version 25 (IBM, Armonk, NY). To create text output according to each frequency band, eLORETA utilities were used and the data were then imported into SPSS, log-transformed to achieve normality, and $z$-transformed for better interpretability.

\section{Results}

Table 1 shows clinical and demographic data collected from the patients with ME/CFS and the HC group. A significant difference between groups was found in the DSQ PEM symptom scores and SF-36 energy/fatigue scores. A lower score on the SF-36 indicates greater disability.

To evaluate group differences in current density for each frequency band at pretest, posttest, and 24 hours (see Figures 1, 2, 3), a mixed multivariate analysis of variance was conducted (age was entered as a covariate). Hotelling's $\tau^{2}$ was employed to describe multivariate tests due to its inherent

\begin{tabular}{|c|c|c|c|}
\hline & ME/CFS $(n=7)$ & $\mathrm{HCs}(n=6)$ & $p$-value \\
\hline $\begin{array}{l}\text { Age } \\
\text { Mean }(S D)\end{array}$ & $54.29( \pm 17.52)$ & $30.51( \pm 5.65)$ & $.008^{\mathrm{a}}$ \\
\hline Sex & $\begin{array}{l}4 \text { Female } \\
3 \text { Male }\end{array}$ & $\begin{array}{l}2 \text { Female } \\
4 \text { Male }\end{array}$ & $.782^{\mathrm{b}}$ \\
\hline Education & $\begin{array}{l}1 \text { Partial college } \\
2 \text { College degree } \\
4 \text { Graduate degree }\end{array}$ & $\begin{array}{l}1 \text { Partial college } \\
3 \text { College degree } \\
2 \text { Graduate degree }\end{array}$ & $.146^{\mathrm{b}}$ \\
\hline Ethnicity & $\begin{array}{l}6 \text { White } \\
1 \text { Asian }\end{array}$ & $\begin{array}{l}3 \text { White } \\
3 \text { Asian }\end{array}$ & $.166^{\mathrm{b}}$ \\
\hline $\begin{array}{l}\text { DSQ PEM Total } \\
\text { Mean }(S D)\end{array}$ & $31.29( \pm 13.03)$ & $8.67( \pm 6.28)$ & $.005^{\mathrm{a}}$ \\
\hline $\begin{array}{l}\text { SF-36 Energy/Fatigue } \\
\text { Mean }(S D)\end{array}$ & $13.57( \pm 5.42)$ & $55( \pm 25.5)$ & $.008^{\mathrm{a}}$ \\
\hline $\begin{array}{l}\text { Illness duration } \\
\text { Mean years }(S D)\end{array}$ & $11.43( \pm 10.39)$ & & \\
\hline
\end{tabular}

${ }^{a}$ Unpaired Mann-Whitney $U$ test

${ }^{\mathrm{b}} X^{2}$ test 
Figure 1. Significant Group Differences at Time 1 (Prehandgrip) for Each Frequency Band Measured During the Eyes-closed Condition.



Note. Comparisons for each frequency band were evaluated as follows: Delta, $p=.052$; Theta, $p=.171$; Alpha-1, $p<.001$; Alpha-2, $p<.001$; Beta-1, $p<.001$; Beta-2, $p<.001$; Beta-3, $p<.001$.

Figure 2. Significant Group Differences at Time 2 (Posthandgrip) for Each Frequency Band Measured During the Eyes-closed Condition.

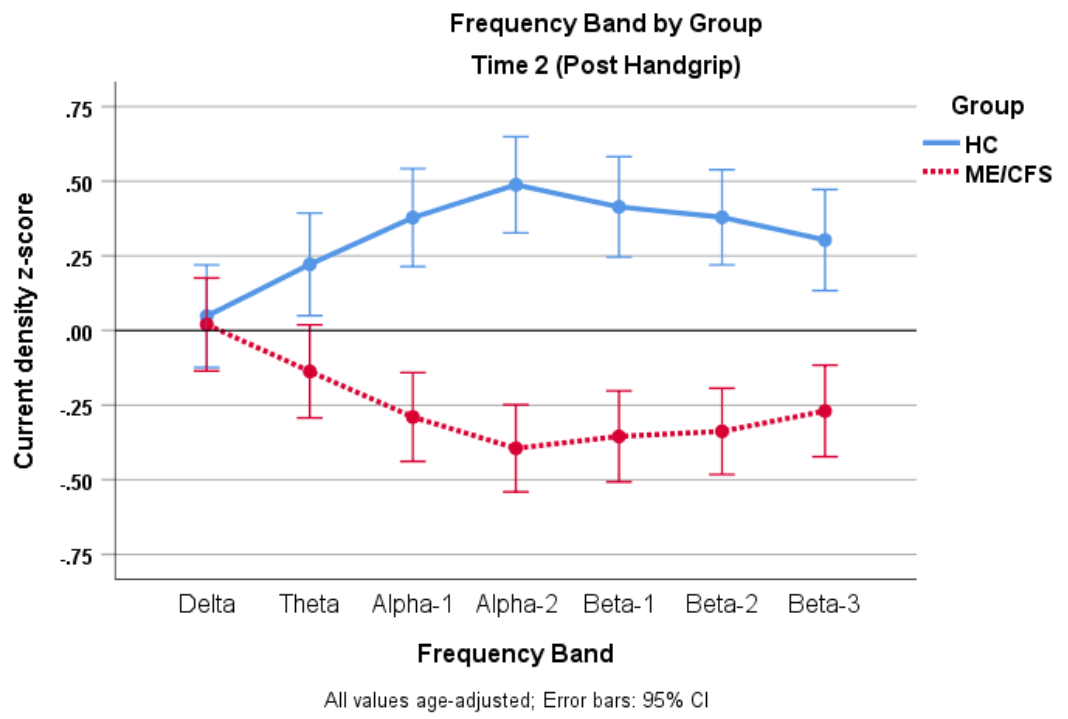

Note. Comparisons for each frequency band were evaluated as follows: Delta, $p=.745$; Theta, $p=.005$; Alpha-1, $p<.001$; Alpha-2, $p<.001$; Beta-1, $p<.001$; Beta-2, $p<.001$; Beta-3, $p<.001$. 
Figure 3. Significant Differences at Time 3 (After 24 Hours) for Each Frequency Band Measured During the Eyes-closed Condition.

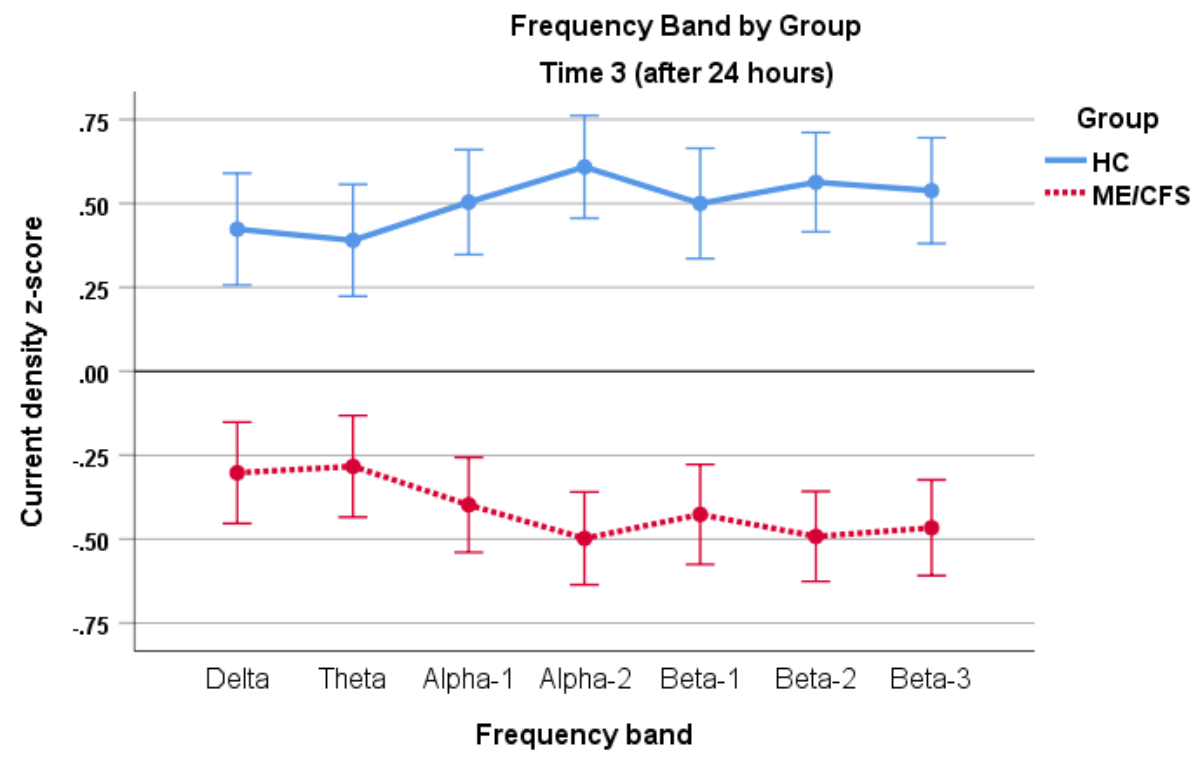

All values age-adjusted; Error Bars: $95 \% \mathrm{Cl}$

Note. Comparisons for each frequency band were evaluated as follows: Delta, $p<.001$; Theta, $p<.001$; Alpha-1, $p<.001$; Alpha-2, $p<.001$; Beta-1, $p<.001$; Beta-2, $p<.001$; Beta-3, $p<.001$.

adjustment for heterogeneity of variances and covariances (multivariate sphericity) when the underlying distributions are normal at each level of the independent variables (Tatsuoka \& Lohnes, 1988). For every outcome, the null hypothesis was tested at the 0.05 level of significance. Bonferroni correction was applied to all comparisons, and adjusted $p$ values are reported.

A statistically significant multivariate effect of current density was found, Hotelling's $\tau^{2}=.459, F(6,395)=$ $30.19, p<.001, \eta^{2}=.31$. HC within-group differences between each time of testing at each frequency band were as follows: Delta, Time 1-2, $p<.001$; Time 1-3, $p<.001$; Time 2-3, $p<.001$. Theta, Time 1-2, $p=.001$; Time 1-3, $p<.001$; Time $2-3, p<.001$. Alpha-1, Time 1-2, $p=.038$; Time $1-3, p<.001$; Time $2-3, p=.001$. Alpha-2, Time $1-$ $2, p=.161$; Time $1-3, p<.001$; Time $2-3, p<.001$. Beta-1, Time 1-2, $p=.99$; Time 1-3, $p=.002$; Time $2-3, p<.001$. Beta-2, Time 1-2, $p=.399$; Time 1-3, $p<.001$; Time 2-3, $p<.001$. Beta-3, Time 1-2, $p=.99$; Time $1-3, p<.001 ;$ Time $2-3, p<.001$.

ME/CFS within-group differences between each time of testing at each frequency band were as follows: Delta, Time 1-2, $p<.001$; Time 1-3, $p<.001$; Time
$2-3, p<.001$. Theta, Time $1-2, p=.002$; Time $1-3$, $p<.001$; Time 2-3, $p<.001$. Alpha-1, Time 1-2, $p=.055 ;$ Time 1-3, $p<.001$; Time 2-3, $p=.001$. Alpha-2, Time 1-2, $p=.203$; Time 1-3, $p<.001$; Time 2-3, $p<.001$. Beta-1, Time 1-2, $p=.99$; Time $1-3, p=.004$; Time 2-3, $p<.001$. Beta-2, Time 1-2, $p=.464 ;$ Time 2-3, $p<.001$; Time $1-3, p<.001$. Beta-3, Time 1-2, $p=.99$; Time 1-3, $p<.001$; Time $2-3, p<.001$. Between Time 1 and Time 2, current density in patients was significantly lower in the delta and theta frequency bands. After 24 hours, however, patients demonstrated a significant reduction in current density across all frequency bands.

A significant effect of group was found, indicating that the differences between patients with ME/CFS and HCs were statistically different, $\tau^{2}=.464, F(6$, $395)=30.54, p<.001, \eta^{2}=.32$, as well as the interaction of time and group, $\tau^{2}=.457, F(2,399)=$ $91.17, p<.001, \eta^{2}=.31$. Current density and time interaction was significant with a medium effect size, $\tau^{2}=1.106, F(12,389)=32.6, p<.001, \eta^{2}=.50$. Finally, there was a significant triple interaction effect of current density and time and group, $\tau^{2}=.732$, $F(12,389)=23.72, p<.001, \eta^{2}=.42($ Figures 1, 2 , 3). 
Next, multilevel logistic regression analyses with a random intercept were conducted to estimate the association between the outcome of current density and variables of interest (time and experimental group), which differed according to each frequency band. Multivariate Hotelling's $\tau^{2} F$-tests from repeated measures analysis of covariance and odds ratios from logistic regression models were used to assess whether the seven prespecified frequency bands in the study were significant by time and experimental group. Adjusted odds ratios (ORs) and $95 \%$ confidence intervals are reported and Bonferroni correction was applied to all comparisons with adjusted $p$ values being reported. The adjusted odds ratios for the likelihood of abnormal current density within each frequency band at each time was estimated for the patients with ME/CFS, using Time 1 as the referent. The final model fit was significant, $\chi^{2}(14)=88.140, p<.001$ (Table 2). Notable changes occurred in the Alpha-1 band, where the odds of dysfunction increased more than two-fold from 7.3 to 16.4 between Time 2 and Time $3(\mathrm{OR}=16.392)$. Similarly, the odds ratio increased nearly five-fold from 3 to 14.3 in the Beta- 1 band $(\mathrm{OR}=14.304)$.

\section{Table 2}

Results of Multilevel Logistic Regression Analysis*

\begin{tabular}{llccr}
\hline & $\begin{array}{c}\text { Frequency } \\
\text { Band }\end{array}$ & $\begin{array}{c}\text { Odds } \\
\text { Ratio }\end{array}$ & $\begin{array}{c}\text { 95\% Confidence Interval } \\
\text { Lower Bound }\end{array}$ & $\begin{array}{c}\text { 95\% Confidence Interval } \\
\text { Upper Bound }\end{array}$ \\
\hline & Delta & 0.500 & 0.294 & 0.850 \\
& Theta & 1.208 & 0.633 & 2.307 \\
Time 2 & Alpha-1 & 7.324 & 2.050 & 26.507 \\
(Posthandgrip) & Alpha-2 & 0.090 & 0.022 & 3.710 \\
& Beta-1 & 3.008 & 1.286 & 0.035 \\
& Beta-2 & 0.169 & 0.075 & 4.63 \\
& Beta-3 & 2.929 & 1.838 & 2.314 \\
Time 3 & Delta & 1.387 & 0.831 & 0.806 \\
Theta & Alpha-1 & 0.422 & 0.221 & 60.092 \\
& Alpha-2 & $16.392^{\mathrm{a}}$ & 4.471 & 0.078 \\
& Beta-1 & 0.018 & 0.004 & 35.153 \\
& Beta-2 & $14.304^{\mathrm{a}}$ & 5.820 & 0.177 \\
& Beta-3 & 0.077 & 0.033 & 4.498 \\
\end{tabular}

* Effects of patients with ME/CFS only at Times 2 and 3 (Time 1 as the referent).

a The odds of CAN dysfunction in the Alpha-1 frequency band for patients with ME/CFS is 7.3 times higher than healthy controls at Time 2, while that odds more than doubled at Time 3 (odds ratio $=16.4$ ). A similar odds increase can be seen in Beta-1.

\section{Discussion}

The present study aimed to quantify the effects of physical exertion on central autonomic function in ME/CFS using eLORETA. The principal finding was a significant time and frequency-dependent pattern of CAN perturbation in the patient group, relative to the HC group. Baseline current density in the patient group was significantly lower in the Alpha and Beta frequency bands, but marginally higher in the Delta band. At Time 2 (posthandgrip), significant physiological changes emerged within both groups: ME/CFS current density was reduced, while HC current density was elevated. This discrepancy between groups occurred in all frequency bands, except Delta. After 24 hours, however, the difference between groups became more pronounced. The ME/CFS group showed a greater reduction in current density whereas the HCs had further increased across all frequency bands.

Secondarily, we found that the odds of CAN dysfunction between Times 1 and 2 and Times 1 and 3 were greater in the Alpha-1 and Beta-1 frequency bands. Different oscillatory frequencies have dissimilar physiological significance, and they represent the temporal modulation of parallel information processing occurring at multiple levels with cyclic variations of intrinsic excitability between different neuronal populations (Buzsáki \& Watson, 
2012). The timings of the Alpha- 1 band have been shown to influence the gating of incoming streams of sensory information that influence task performance (Busch et al., 2009). Thus, a greater likelihood of Alpha-1 dysfunction in patients suggests they are prone to experience problems with central drive mechanisms that influence sensorimotor processing of fatigue during physical exercise. Likewise, the Beta band $(\sim 13-30 \mathrm{~Hz})$ is arrhythmic, low voltage activity associated with alertness, and studies have demonstrated its role in cognitive processing of attention and working memory (Heister et al., 2013; Palva et al., 2005). Higher odds ratios in Beta- 1 $(\sim 13-18 \mathrm{~Hz})$ activity might be a reflection of persistent cognitive deficits associated with ME/CFS (Cockshell \& Mathias, 2014; Güntekin et al., 2013).

Together, these results are consistent with the characteristic stamina loss and behavioral worsening of symptoms in PEM after 24 hours and they extend previous investigations showing aberrant CNS signaling followed by fatigue-inducing voluntary motor tasks (Benwell et al., 2006; Hilty, Jäncke, et al., 2011; Schillings et al., 2005; Siemionow et al., 2004; Zwarts et al., 2008). Our prediction that the HC group would return to baseline after 24 hours was not confirmed, and their current density was even higher. One possible explanation involves the modification of homeostatic mechanisms that initiate physiological changes in excitatory drive and motor control of ANS outflow. According to a central fatigue model (Amann \& Calbet, 2008), planning, execution, and control of voluntary muscle tasks are regulated by alterations to neurotransmitter levels and $\mathrm{O}_{2}$ delivery which are governed by homeostatic mechanisms in the CNS in response to physical challenge. The isometric handgrip task is known to elicit sympathetic activity which stimulates the baroreceptors in the sinoatrial node of the heart through activation of the nucleus tractus solitarius (NTS; Topolovec et al., 2004). The NTS, in turn, innervates the locus coeruleus (LC) of the rostral pons of the brainstem, a nucleus which is the primary source of norepinephrine (NE) in the brain (Sharma et al., 2010). NE promotes an enhanced signal/noise ratio in sensorimotor processing and ascending arousal system responses and, acting through thalamic nuclei and sensory cortices, mediates gating and tuning influences in coordinating experience-dependent alterations to pain processing, motor control, and local blood flow (Cutsforth-Gregory \& Benarroch, 2017). Consistent with central fatigue, the handgrip task was demonstrated to activate the mid/anterior insula which processes nociceptive cues to homeostatic disturbances (Hilty, Jäncke, et al.,
2011). The insula processes interoception and has extensive connections with the hypothalamus for the regulation of neuroendocrine responses to physical stimuli (Allen et al., 1991). Basal cortisol has been consistently reported to be significantly lower in patients with ME/CFS (Demitrack et al., 1991; Papadopoulos \& Cleare, 2012; Parker et al., 2001; Van Den Eede et al., 2007) possibly leading to reductions in cortical activity we found.

To date, this is the first study using eLORETA to examine CAN structures that may underlie disturbances in PEM. However, this was a pilot study intended to provide groundwork for a larger scale study without sample size limitations. Thus, given the small sample size of each group, the differences found here must be interpreted with caution. In addition, only diffuse changes in CAN activity were reported here, but a larger study would have potential to evaluate differences in activity for each separate region of interest. Moreover, the inclusion of autonomic measures in future studies would be beneficial to making stronger association of CAN disturbances with autonomic dysfunction in $\mathrm{ME} / \mathrm{CFS}$. Next, we recognize that eLORETA source estimations are restricted to cortical regions of interest and several subcortical regions of the CAN (thalamus, red nucleus, cerebellum) were excluded from the analyses. However, findings of cortical pathology implicate these subcortical structures due to their reentrant circuitry with cortico-subcortical fibers. Finally, significant changes to baseline current density were found in both groups after 24 hours, and future studies could include additional follow-up EEG recordings made at 48 and 72 hours to capture the pace and duration of patient recovery patterns and eventual return to baseline.

In conclusion, this study offers important preliminary evidence for CAN involvement in the episodic manifestations of PEM in patients with ME/CFS. If confirmed, the CAN current density may serve as an index of PEM for aiding diagnosis and treatment outcomes. Furthermore, this study demonstrates the feasibility of eLORETA as a practical tool for investigating $P E M$ and revealing the neuropathic mechanisms in ME/CFS.

Author Note

Sponsored by DePaul University. There were no sources of funding for this study.

Author Disclosure

None of the authors have potential conflicts of interest to be disclosed. 


\section{References}

Allen, G. V., Saper, C. B., Hurley, K. M., \& Cechetto, D. F. (1991). Organization of visceral and limbic connections in the insular cortex of the rat. The Journal of Comparative Neurology, 311(1), 1-16. https://doi.org/10.1002/cne.903110102

Amann, M., \& Calbet, J. A. L. (2008). Convective oxygen transport and fatigue. Journal of Applied Physiology, 104(3), 861-870. https://doi.org/10.1152/japplphysiol.01008.2007

Aoki, Y., Kazui, H., Pascal-Marqui, R. D., Ishii, R., Yoshiyama, K., Kanemoto, H., Suzuki, Y., Sato, S., Hata, M., Canuet, L., Iwase, M., \& Ikeda, M. (2019). EEG resting-state networks in dementia with Lewy bodies associated with clinical symptoms. Neuropsychobiology, 77(4), 206-218. https://doi.org/10.1159/000495620

Babiloni, C., Visser, P. J., Frisoni, G., De Deyn, P. P., Bresciani, L., Jelic, V., Nagels, G., Rodriguez, G., Rossini, P. M., Vecchio, F., Colombo, D., Verhey, F., Wahlund, L.-O., \& Nobili, F. (2010). Cortical sources of resting EEG rhythms in mild cognitive impairment and subjective memory complaint. Neurobiology of Aging, 31(10), 1787-1798. https://doi.org /10.1016/j.neurobiolaging.2008.09.020

Bansal, A. S., Bradley, A. S., Bishop, K. N., Kiani-Alikhan, S., \& Ford, B. (2012). Chronic fatigue syndrome, the immune system and viral infection. Brain, Behavior, and Immunity, 26(1), 24-31. https://doi.org/10.1016/j.bbi.2011.06.016

Barah, F., Whiteside, S., Batista, S., \& Morris, J. (2014). Neurological aspects of human parvovirus B19 infection: A systematic review. Reviews in Medical Virology, 24(3), 154168. https://doi.org/10.1002/rmv.1782

Barnden, L. R., Kwiatek, R., Crouch, B., Burnet, R., \& Del Fante, P. (2016). Autonomic correlations with MRI are abnormal in the brainstem vasomotor centre in Chronic Fatigue Syndrome. Neurolmage: Clinical, 11, 530-537. https://doi.org /10.1016/j.nicl.2016.03.017

Beaumont, A., Burton, A. R., Lemon, J., Bennett, B. K., Lloyd, A., \& Vollmer-Conna, U. (2012). Reduced cardiac vagal modulation impacts on cognitive performance in chronic fatigue syndrome. PLOS ONE, 7(11), e49518. https://doi.org/10.1371/journal.pone.0049518

Beissner, F., Meissner, K., Bär, K. J., \& Napadow, V. (2013). The autonomic brain: An activation likelihood estimation metaanalysis for central processing of autonomic function. The Journal of Neuroscience, 33(25), 10503-10511. https://doi.org/10.1523/jneurosci.1103-13.2013

Benarroch, E. E. (1993). The central autonomic network: Functional organization, dysfunction, and perspective. Mayo Clinic Proceedings, 68(10), 988-1001. https://doi.org/10.1016 /s0025-6196(12)62272-1

Benarroch, E. E. (2012). Central autonomic control. In D. Robertson, I. Biaggioni, G. Burnstock, P. A. Low, \& J. F. R. Paton (Eds.), Primer on the autonomic nervous system (3rd ed., pp. 9-12). Amsterdam, NL: Elsevier.

Benarroch, E. E. (2019). Autonomic nervous system and neuroimmune interactions. Neurology, 92(8), 377-385. https://doi.org/10.1212/WNL.0000000000006942

Benwell, N. M., Mastaglia, F. L., \& Thickbroom, G. W. (2006). Reduced functional activation after fatiguing exercise is not confined to primary motor areas. Experimental Brain Research, 175(4), 575-583. https://doi.org/10.1007/s00221006-0573-9

Berelowitz, G. J., Burgess, A. P., Thanabalasingham, T., MurrayLyon, I. M., \& Wright, D. J. M. (1995). Post-hepatitis syndrome revisited. Journal of Viral Hepatitis, 2(3), 133-138.

Bozzini, S., Albergati, A., Capelli, E., Lorusso, L., Gazzaruso, C., Pelissero, G., \& Falcone, C. (2018). Cardiovascular characteristics of chronic fatigue syndrome. Biomedical Reports, 8(1), 26-30. https://doi.org/10.3892/br.2017.1024
Brett, M., Johnsrude, I. S., \& Owen, A. M. (2002). The problem of functional localization in the human brain. Nature Reviews Neuroscience, 3(3), 243-249. https://doi.org/10.1038/nrn756

Busch, N. A., Dubois, J., \& VanRullen, R. (2009). The phase of ongoing EEG oscillations predicts visual perception. Journal of Neuroscience, 29(24), 7869-7876. https://doi.org/10.1523 /jneurosci.0113-09.2009

Buzsáki, G., \& Watson, B. O. (2012). Brain rhythms and neural syntax: Implications for efficient coding of cognitive content and neuropsychiatric disease. Dialogues in Clinical Neuroscience, 14(4), 345-367. https://doi.org/10.31887 /dcns.2012.14.4/gbuzsaki

Cambras, T., Castro-Marrero, J., Zaragoza, M. C., Díez-Noguera, A., \& Alegre, J. (2018). Circadian rhythm abnormalities and autonomic dysfunction in patients with chronic fatigue syndrome/myalgic encephalomyelitis. PLOS ONE, 13(6), e0198106. https://doi.org/10.1371/journal.pone.0198106

Canuet, L., Tellado, I., Couceiro, V., Fraile, C., Fernandez-Novoa, L., Ishii, R., Takeda, M., \& Cacabelos, R. (2012). Restingstate network disruption and APOE genotype in Alzheimer's disease: A lagged functional connectivity study. PLOS ONE, 7(9), e46289. https://doi.org/10.1371/journal.pone.0046289

Cao, C., \& Slobounov, S. (2010). Alteration of cortical functional connectivity as a result of traumatic brain injury revealed by graph theory, ICA, and sLORETA analyses of EEG signals. IEEE Transactions on Neural Systems and Rehabillitation Engineering, 18(1), 11-19. https://doi.org/10.1109 /tnsre.2009.2027704

Carruthers, B. M., Jain, A. K., De Meirleir, K. L., Peterson, D. L., Klimas, N. G., Lerner, A. M., Bested, A. C., Flor-Henry, P., Joshi, P., Powles, A. C. P., Sherkey, J. A., \& van de Sande, M. I. (2003). Myalgic encephalomyelitis/chronic fatigue syndrome. Journal of Chronic Fatigue Syndrome, 11(1), 7115. https://doi.org/10.1300/J092v11n01_02

Carruthers, B. M., van de Sande, M. I., De Meirleir, K. L., Klimas, N. G., Broderick, G., Mitchell, T., Staines, D., Powles, A. C. P., Speight, N., Vallings, R., Bateman, L., BaumgartenAustrheim, B., Bell, D. S., Carlo-Stella, N., Chia, J., Darragh, A., Jo, D., Lewis, D., Light, A. R., Marshall-Gradisbik, S., ... Stevens, S. (2011). Myalgic encephalomyelitis: International consensus criteria. Journal of Internal Medicine, 270(4), 327338. https://doi.org/10.1111/j.1365-2796.2011.02428.x

Caso, F., Cursi, M., Magnani, G., Fanelli, G., Falautano, M., Comi, G., Leocani, L., \& Minicucci, F. (2012). Quantitative EEG and LORETA: Valuable tools in discerning FTD from AD? Neurobiology of Aging, 33(10), 2343-2356. https://doi.org/10.1016/j.neurobiolaging.2011.12.011

Chaudhuri, A., \& Behan, P. O. (2004). Fatigue in neurological disorders. The Lancet, 363(9413), 978-988. https://doi.org /10.1016/S0140-6736(04)15794-2

Chen, R., Liang, F. X., Moriya, J., Yamakawa, J., Sumino, H., Kanda, T., \& Takahashi, T. (2008). Chronic fatigue syndrome and the central nervous system. Journal of International Medical Research, 36(5), 867-874.

Cho, H. J., Skowera, A., Cleare, A., \& Wessely, S. (2006). Chronic fatigue syndrome: An update focusing on phenomenology and pathophysiology. Current Opinion in Psychiatry, 19(1), 67-73. https://doi.org/10.1097 /01.yco.0000194370.40062.b0

Cleare, A. J. (2004). The HPA axis and the genesis of chronic fatigue syndrome. Trends in Endocrinology \& Metabolism, 15(2), 55-59. https://doi.org/10.1016/j.tem.2003.12.002

Clemens, B., Bánk, J., Piros, P., Bessenyei, M., Veto, S., Tóth, M., \& Kondákor, I. (2008). Three-dimensional localization of abnormal EEG activity in migraine: A low resolution electromagnetic tomography (LORETA) study of migraine patients in the pain-free interval. Brain Topography, 21(1), 36-42. https://doi.org/10.1007/s10548-008-0061-6

Clemens, B., Bessenyei, M., Fekete, I., Puskás, S., Kondákor, I. Tóth, M., \& Hollódy, K. (2010). Theta EEG source localization 
using LORETA in partial epilepsy patients with and without medication. Clinical Neurophysiology, 121(6), 848-858. https://doi.org/10.1016/j.clinph.2010.01.020

Cockshell, S. J., \& Mathias, J. L. (2014). Cognitive functioning in people with chronic fatigue syndrome: A comparison between subjective and objective measures. Neuropsychology, 28(3), 394-405. https://doi.org/10.1037/neu0000025

Cook, D. B., Stegner, A. J., Nagelkirk, P. R., Meyer, J. D., Togo, F., \& Natelson, B. H. (2012). Responses to exercise differ for chronic fatigue syndrome patients with fibromyalgia. Medicine \& Science in Sports \& Exercise, 44(6), 1186-1193. https://doi.org/10.1249/MSS.0b013e3182417b9a

Cutsforth-Gregory, J. K., \& Benarroch, E. E. (2017). Nucleus of the solitary tract, medullary reflexes, and clinical implications. Neurology, $\quad 88(12), \quad 1187 . \quad$ https://doi.org/10.1212 WNL.0000000000003751

Cvejic, E., Sandler, C. X., Keech, A., Barry, B. K., Lloyd, A. R., \& Vollmer-Conna, U. (2017). Autonomic nervous system function, activity patterns, and sleep after physical or cognitive challenge in people with chronic fatigue syndrome. Journal of Psychosomatic Research, 103, 91-94. https://doi.org/10.1016/j.jpsychores.2017.10.010

Demitrack, M. A., Dale, J. K., Straus, S. E., Laue, L., Listwak, S. J., Kruesi, M. J., Chrousos, G. P., \& Gold, P. W. (1991). Evidence for impaired activation of the hypothalamic-pituitaryadrenal axis in patients with chronic fatigue syndrome. The Journal of Clinical Endocrinology \& Metabolism, 73(6), 12241234. https://doi.org/10.1210/jcem-73-6-1224

Dierks, T., Jelic, V., Pascual-Marqui, R. D., Wahlund, L.-O., Julin, P., Linden, D. E. J., Maurer, K., Winblad, B., \& Nordberg, A. (2000). Spatial pattern of cerebral glucose metabolism (PET) correlates with localization of intracerebral EEG-generators in Alzheimer's disease. Clinical Neurophysiology, 111(10), 1817-1824. https://doi.org/10.1016/s1388-2457(00)00427-2

Fuchs, M., Kastner, J., Wagner, M., Hawes, S., \& Ebersole, J. S. (2002). A standardized boundary element method volume conductor model. Clinical Neurophysiology, 113(5), 702-712. https://doi.org/10.1016/S1388-2457(02)00030-5

Fukuda, K., Straus, S. E., Hickie, I., Sharpe, M. C., Dobbins, J. G., \& Komaroff, A. (1994). The chronic fatigue syndrome: A comprehensive approach to its definition and study. Annals of Internal Medicine, 121(12), 953-959. https://doi.org/10.7326 /0003-4819-121-12-199412150-00009

Gianotti, L. R. R., Künig, G., Lehmann, D., Faber, P. L., PascualMarqui, R. D., Kochi, K., \& Schreiter-Gasser, U. (2007). Correlation between disease severity and brain electric LORETA tomography in Alzheimer's disease. Clinical Neurophysiology, 118(1), 186-196. https://doi.org/10.1016 /j.clinph.2006.09.007

Grech, R., Cassar, T., Muscat, J., Camilleri, K. P., Fabri, S. G., Zervakis, M., Xanthopoulos, P., Sakkalis, V., \& Vanrumste, B. (2008). Review on solving the inverse problem in EEG source analysis. Journal of NeuroEngineering and Rehabilitation, 5, 25. https://doi.org/10.1186/1743-0003-5-25

Güntekin, B., Emek-Savas, D. D., Kurt, P., Yener, G. G., \& Basar, E. (2013). Beta oscillatory responses in healthy subjects and subjects with mild cognitive impairment. Neurolmage: Clinical, 3, 39-46. https://doi.org/10.1016/j.nicl.2013.07.003

Gunzelmann, G., James, S. M., \& Caldwell, J. L. (2019). Basic and applied science interactions in fatigue understanding and risk mitigation. Progress in Brain Research, 246, 177-204. https://doi.org/10.1016/bs.pbr.2019.03.022

Harris, P. A., Taylor, R., Thielke, R., Payne, J., Gonzalez, N., \& Conde, J. G. (2009). Research electronic data capture (REDCap)-A metadata-driven methodology and workflow process for providing translational research informatics support. Journal of Biomedical Informatics, 42(2), 377-381. https://doi.org/10.1016/j.jbi.2008.08.010

Hata, M., Kazui, H., Tanaka, T., Ishii, R., Canuet, L., PascualMarqui, R. D., Aoki, Y., Ikeda, S., Kanemoto, H., Yoshiyama,
K., Iwase, M., \& Takeda, M. (2016). Functional connectivity assessed by resting state EEG correlates with cognitive decline of Alzheimer's disease: An eLORETA study. Clinical Neurophysiology, 127(2), 1269-1278. https://doi.org/10.1016 /j.clinph.2015.10.030

Heister, D., Diwakar, M., Nichols, S., Robb, A., Angeles, A. M., Tal, O., Harrington, D. L., Song, T., Lee, R. R., \& Huang, M. (2013). Resting-state neuronal oscillatory correlates of working memory performance. PLOS ONE, 8(6), e66820. https://doi.org/10.1371/journal.pone.0066820

Hilty, L., Jäncke, L., Luechinger, R., Boutellier, U., \& Lutz, K. (2011). Limitation of physical performance in a muscle fatiguing handgrip exercise is mediated by thalamo-insular activity. Human Brain Mapping, 32(12), 2151-2160. https://doi.org/10.1002/hbm.21177

Holgate, S. T., Komaroff, A. L., Mangan, D., \& Wessely, S. (2011). Chronic fatigue syndrome: Understanding a complex illness. Nature Reviews Neuroscience, 12(9), 539-544. https://doi.org/10.1038/nrn3087

Ickmans, K., Meeus, M., De Kooning, M., Lambrecht, L., Pattyn, N., \& Nijs, J. (2014). Can recovery of peripheral muscle function predict cognitive task performance in chronic fatigue syndrome with and without fibromyalgia? Physical Therapy, 94(4), 511-522. https://doi.org/10.2522/ptj.20130367

Institute of Medicine. (2015). Beyond myalgic encephalomyelitis/chronic fatigue syndrome: Redefining an Illness. Washington, DC: The National Academies Press. https://doi.org/10.17226/19012

Jammes, Y., Stavris, C., Charpin, C., Rebaudet, S., Lagrange, G., \& Retornaz, F. (2020). Maximal handgrip strength can predict maximal physical performance in patients with chronic fatigue. Clinical Biomechanics, 73, 162-165. https://doi.org /10.1016/j.clinbiomech.2020.01.003

Jason, L. A., Evans, M., Porter, N., Brown, A., Brown, M., Hunnell, J., Anderson, V., Lerch, A., De Meirleir, K., \& Friedberg, F. (2010). The development of a revised Canadian myalgic encephalomyelitis-chronic fatigue syndrome case definition. American Journal of Biochemistry and Biotechnology, 6(2), 120-135. https://doi.org/10.3844 lajbbsp.2010.120.135

Jason, L. A., So, S., Brown, A. A., Sunnquist, M., \& Evans, M. (2015). Test-retest reliability of the DePaul Symptom Questionnaire. Fatigue: Biomedicine, Health \& Behavior, 3(1), 16-32. https://doi.org/10.1080/21641846.2014.978110

Jeppesen, T. D., Quistorff, B., Wibrand, F., \& Vissing, J. (2007). ${ }^{31} \mathrm{P}-\mathrm{MRS}$ of skeletal muscle is not a sensitive diagnostic test for mitochondrial myopathy. Journal of Neurology, 254(1), 29-37. https://doi.org/10.1007/s00415-006-0229-5

Kaiser, D. A. \& Sterman, M. B. (2000). Automatic artifact detection, overlapping windows, and state transitions. Journal of Neurotherapy, 4(3), 85-92. https://doi.org/10.1300 IJ184v04n03 06

LaManca, J. J., Sisto, S. A., DeLuca, J., Johnson, S. K., Lange, G., Pareja, J., Cook, S., \& Natelson, B. H. (1998). Influence of exhaustive treadmill exercise on cognitive functioning in chronic fatigue syndrome. The American Journal of Medicine, 105(3, Suppl. 1), 59S-65S. https://doi.org/10.1016/s00029343(98)00171-5

Lancaster, J. L., Woldorff, M. G., Parsons, L. M., Liotti, M., Freitas, C. S., Rainey, L., Kochunov, P. V., Nickerson, D., Mikiten, S. A., \& Fox, P. T. (2000). Automated Talairach atlas labels for functional brain mapping. Human Brain Mapping, 10(3), 120-131. https://doi.org/10.1002/10970193(200007)10:3\%3C120::aid-hbm30\%3E3.0.co;2-8

Lantz, G., Michel, C. M., Pascual-Marqui, R. D., Spinelli, L., Seeck, M., Seri, S., Landis, T., \& Rosen, I. (1997). Extracranial localization of intracranial interictal epileptiform activity using LORETA (low resolution electromagnetic tomography). Electroencephalography and Clinical 
Neurophysiology, 102(5), 414-422. https://doi.org/10.1016 /s0921-884x(96)96551-0

Light, A. R., Bateman, L., Jo, D., Hughen, R. W., VanHaitsma, T. A., White, A. T., \& Light, K. C. (2012). Gene expression alterations at baseline and following moderate exercise in patients with chronic fatigue syndrome and fibromyalgia syndrome. Journal of Internal Medicine, 271(1), 64-81. https://doi.org/10.1111/j.1365-2796.2011.02405.x

Light, A. R., White, A. T., Hughen, R. W., \& Light, K. C. (2009). Moderate exercise increases expression for sensory adrenergic and immune genes in chronic fatigue syndrome patients but not in normal subjects. The Journal of Pain, 10(10), 1099-1112. https://doi.org/10.1016 /j.jpain.2009.06.003

Loebel, M., Strohschein, K., Giannini, C., Koelsch, U., Bauer, S., Doebis, C., Thomas, S., Unterwalder, N., von Baehr, V., Reinke, P., Knops, M., Hanitsch, L. G., Meisel, C., Volk, H.D., \& Scheibenbogen, C. (2014). Deficient EBV-specific Band T-cell response in patients with chronic fatigue syndrome. PLoS ONE, 9(1), e85387. https://doi.org/10.1371 /journal.pone.0085387

Lubar, J. F., Congedo, M., \& Askew, J. H. (2003). Low-resolution electromagnetic tomography (LORETA) of cerebral activity in chronic depressive disorder. International Journal of Psychophysiology, 49(3), 175-185. https://doi.org/10.1016 /S0167-8760(03)00115-6

Maes, M., Twisk, F. N. M., Kubera, M., \& Ringel, K. (2012). Evidence for inflammation and activation of cell-mediated immunity in myalgic encephalomyelitis/chronic fatigue syndrome (ME/CFS): Increased interleukin-1, tumor necrosis factor-alpha, PMN-elastase, lysozyme and neopterin. Journal of Affective Disorders, 136(3), 933-939. https://doi.org /10.1016/j.jad.2011.09.004

Mathias, C. J., \& Bannister, R. (Eds.). (2013). Autonomic failure: A textbook of clinical disorders of the autonomic nervous system (5th ed.). Oxford, UK: Oxford Univeristy Press. https://doi.org/10.1093/med/9780198566342.001.0001

Mazziotta, J., Toga, A., Evans, A., Fox, P., Lancaster, J., Zilles, K., Woods, R., Paus, T., Simpson, G., Pike, B., Holmes, C., Collins, L., Thompson, P., MacDonald, D., lacoboni, M., Schormann, T., Amunts, K., Palomero-Gallagher, N., Geyer, S., Parsons, L., ... Mazoyer, B. (2001). A probabilistic atlas and reference system for the human brain: International Consortium for Brain Mapping (ICBM). Philosophical Transactions of the Royal Society B: Biological Sciences, 356(1412), 1293-1322. https://doi.org/10.1098 /rstb.2001.0915

McEwen, B. S., Bowles, N. P., Gray, J. D., Hill, M. N., Hunter, R. G., Karatsoreos, I. N., \& Nasca, C. (2015). Mechanisms of stress in the brain. Nature Neuroscience, 18(10), 1353-1363. https://doi.org/10.1038/nn.4086

Meeus, M., Nijs, J., \& De Meirleir, K. (2007). Chronic musculoskeletal pain in patients with the chronic fatigue syndrome: A systematic review. European Journal of Pain, 11(4), 377-386. https://doi.org/10.1016/j.ejpain.2006.06.005

Meulemans, A., Gerlo, E., Seneca, S., Lissens, W., Smet, J., Van Coster, R., \& De Meirleir, L. (2007). The aerobic forearm exercise test, a non-invasive tool to screen for mitochondrial disorders. Acta Neurologica Belgica, 107(3), 78-83.

Miraglia, F., Tomino, C., Vecchio, F., Alù, F., Orticoni, A., Judica, E., Cotelli, M., \& Rossini, P. M. (2021). Assessing the dependence of the number of EEG channels in the brain networks' modulations. Brain Research Bulletin, 167, 33-36. https://doi.org/10.1016/j.brainresbull.2020.11.014

Mo, J., Huang, L., Peng, J., Ocak, U., Zhang, J., \& Zhang, J. H. (2019). Autonomic disturbances in acute cerebrovascular disease. Neuroscience Bulletin, 35(1), 133-144. https://doi.org/10.1007/s12264-018-0299-2
Morrison, S. F., \& Nakamura, K. (2019). Central mechanisms for thermoregulation. Annual Review of Physiology, 81(1), 285308. https://doi.org/10.1146/annurev-physiol-020518-114546

Mulert, C., Jäger, L., Schmitt, R., Bussfeld, P., Pogarell, O., Möller, H. J., Juckel, G., \& Hegerl, U. (2004). Integration of fMRI and simultaneous EEG: towards a comprehensive understanding of localization and time-course of brain activity in target detection. Neurolmage, 22(1), 83-94. https://doi.org/10.1016/j.neuroimage.2003.10.051

Nacul, L. C., Mudie, K., Kingdon, C. C., Clark, T. G., \& Lacerda, E. M. (2018). Hand grip strength as a clinical biomarker for ME/CFS and disease severity. Frontiers in Neurology, 9, 992. https://doi.org/10.3389/fneur.2018.00992

Nakatomi, Y., Mizuno, K., Ishii, A., Wada, Y., Tanaka, M. Tazawa, S., Onoe, K., Fukuda, S., Kawabe, J., Takahashi, K., Kataoka, Y., Shiomi, S., Yamaguti, K., Inaba, M., Kuratsune, H., \& Watanabe, Y. (2014). Neuroinflammation in patients with chronic fatigue syndrome/myalgic encephalomyelitis: An ${ }^{11} \mathrm{C}-(\mathrm{R})-\mathrm{PK} 11195$ PET study. Journal of Nuclear Medicine, 55(6), 945-950. https://doi.org/10.2967 /jnumed.113.131045

Naviaux, R. K., Naviaux, J. C., Li, K., Bright, A. T., Alaynick, W. A., Wang, L., Baxter, A., Nathan, N., Anderson, W., \& Gordon, E. (2016). Metabolic features of chronic fatigue syndrome. Proceedings of the National Academy of Sciences of the United States of America, 113(37), E5472-E5480. https://doi.org/10.1073/pnas.1607571113

Neu, D., Mairesse, O., Montana, X., Gilson, M., Corazza, F., Lefevre, N., Linkowski, P., Le Bon, O., \& Verbanck, P. (2014). Dimensions of pure chronic fatigue: Psychophysical, cognitive and biological correlates in the chronic fatigue syndrome. European Journal of Applied Physiology, 114(9), 1841-1851. https://doi.org/10.1007/s00421-014-2910-1

Nielsen, S. E., \& Mather, M. (2015). Comparison of two isometric handgrip protocols on sympathetic arousal in women. Physiology \& Behavior, 142, 5-13. https://doi.org/10.1016 /j.physbeh.2015.01.031

Nijs, J., Van Oosterwijck, J., Meeus, M., Lambrecht, L., Metzger, K., Frémont, M., \& Paul, L. (2010). Unravelling the nature of postexertional malaise in myalgic encephalomyelitis/chronic fatigue syndrome: The role of elastase, complement C4a and interleukin-1beta. Journal of Internal Medicine, 267(4), 418435. https://doi.org/10.1111/j.1365-2796.2009.02178.x

Nishida, K., Yoshimura, M., Isotani, T., Yoshida, T., Kitaura, Y., Saito, A., Mii, H., Kato, M., Takekita, Y., Suwa, A., Morita, S., \& Kinoshita, T. (2011). Differences in quantitative EEG between frontotemporal dementia and Alzheimer's disease as revealed by LORETA. Clinical Neurophysiology, 122(9), 1718-1725. https://doi.org/10.1016/j.clinph.2011.02.011

Norman, K., Stobäus, N., Smoliner, C., Zocher, D., Scheufele, R., Valentini, L., Lochs, H., \& Pirlich, M. (2010). Determinants of hand grip strength, knee extension strength and functional status in cancer patients. Clinical Nutrition, 29(5), 586-591. https://doi.org/10.1016/j.clnu.2010.02.007

Ohashi, K., Yamamoto, Y., \& Natelson, B. H. (2002). Activity rhythm degrades after strenuous exercise in chronic fatigue syndrome. Physiology \& Behavior, 77(1), 39-44. https://doi.org/10.1016/s0031-9384(02)00808-9

Oosterwijck, J. V., Marusic, U., De Wandele, I., Paul, L., Meeus, M., Moorkens, G., Lambrecht, L., Danneels, L., \& Nijs, J. (2017). The role of autonomic function in exercise-induced endogenous analgesia: A case-control study in myalgic encephalomyelitis/chronic fatigue syndrome and healthy people. Pain Physician, 20(3), E389-E399.

Orjatsalo, M., Alakuijala, A., \& Partinen, M. (2018). Autonomic nervous system functioning related to nocturnal sleep in patients with chronic fatigue syndrome compared to tired controls. Journal of Clinical Sleep Medicine, 14(2), 163-171. https://doi.org/10.5664/jcsm.6924

Pajediene, E., Bileviciute-Ljungar, I., \& Friberg, D. (2018). Sleep patterns among patients with chronic fatigue: A 
polysomnography-based study. The Clinical Respiratory Journal, 12(4), 1389-1397. https://doi.org/10.1111/crj.12667

Palva, J. M., Palva, S., \& Kaila, K. (2005). Phase synchrony among neuronal oscillations in the human cortex. The Journal of Neuroscience, 25(15), 3962-3972. https://doi.org/10.1523 /jneurosci.4250-04.2005

Papadopoulos, A. S., \& Cleare, A. J. (2012). Hypothalamicpituitary-adrenal axis dysfunction in chronic fatigue syndrome. Nature Reviews Endocrinology, 8(1), 22-32. https://doi.org /10.1038/nrendo.2011.153

Parker, A. J., Wessely, S., \& Cleare, A. J. (2001). The neuroendocrinology of chronic fatigue syndrome and fibromyalgia. Psychological Medicine, 31(8), 1331-1345. https://doi.org/10.1017/s0033291701004664

Pascarelli, M. T., Del Percio, C., De Pandis, M. F., Ferri, R., Lizio, R., Noce, G., Lopez, S., Rizzo, M., Soricelli, A., Nobili, F., Arnaldi, D., Famà, F., Orzi, F., Buttinelli, C., Giubilei, F., Salvetti, M., Cipollini, V., Franciotti, R., Onofri, M., Fuhr, R., ... Babiloni, C. (2020). Abnormalities of resting-state EEG in patients with prodromal and overt dementia with Lewy bodies: Relation to clinical symptoms. Clinical Neurophysiology, 131(11), 2716-2731. https://doi.org/10.1016 /j.clinph.2020.09.004

Pascual-Marqui, R. D. (2002). Standardized low-resolution brain electromagnetic tomography (sLORETA): Technical details. Methods \& Findings in Experimental \& Clinical Pharmacology, 24(Suppl. D), 5-12.

Pascual-Marqui, R. D., Lehmann, D., Koukkou, M., Kochi, K., Anderer, P., Saletu, B., Tanaka, H., Hirata, K., John, E. R., Prichep, L., Biscay-Lirio, R., \& Kinoshita, T. (2011). Assessing interactions in the brain with exact low-resolution electromagnetic tomography. Philosophical Transactions of the Royal Society A, 369(1952), 3768-3784. https://doi.org /10.1098/rsta.2011.0081

Pascual-Marqui, R. D., Michel, C. M., \& Lehmann, D. (1994). Low resolution electromagnetic tomography: $A$ new method for localizing electrical activity in the brain. International Journal of Psychophysiology, 18(1), 49-65. https://doi.org/10.1016 /0167-8760(84)90014-x

Pendergrast, T., Brown, A., Sunnquist, M., Jantke, R., Newton, J. L., Strand, E. B., \& Jason, L. A. (2016). Housebound versus nonhousebound patients with myalgic encephalomyelitis and chronic fatigue syndrome. Chronic Illness, 12(4), 292-307. https://doi.org/10.1177/1742395316644770

Pfaff, D. W., Kieffer, B. L., \& Swanson, L. W. (2008). Mechanisms for the regulation of state changes in the central nervous system. Annals of the New York Academy of Sciences, 1129(1), 1-7. https://doi.org/10.1196/annals.1417.031

Pizzagalli, D. A., Oakes, T. R., Fox, A. S., Chung, M. K., Larson, C. L., Abercrombie, H. C., Schaefer, S. M., Benca, R. M., \& Davidson, R. J. (2004). Functional but not structural subgenual prefrontal cortex abnormalities in melancholia. Molecular Psychiatry, 9(4), 393-405. https://doi.org/10.1038 /sj.mp.4001469

Porges, S. W. (1992). Vagal tone: A physiologic marker of stress vulnerability. Pediatrics, 90(3 Pt 2), 498-504.

Porges, S. W. (2009). The polyvagal theory: New insights into adaptive reactions of the autonomic nervous system. Cleveland Clinic Journal of Medicine, 76(4 Suppl. 2), S86S90. https://doi.org/10.3949/ccjm.76.s2.17

Rasa, S., Nora-Krukle, Z., Henning, N., Eliassen, E., Shikova, E., Harrer, T., Scheibenbogen, C., Murovska, M., Prusty, B. K., \& European Network on ME/CFS (EUROMENE). (2018). Chronic viral infections in myalgic encephalomyelitis/chronic fatigue syndrome (ME/CFS). Journal of Translational Medicine, 16(1), 268. https://doi.org/10.1186/s12967-0181644-y

Roerink, M. E., Roerink, S. H. P. P., Skoluda, N., van der Schaaf, M. E., Hermus, A. R. M. M., van der Meer, J. W. M., Knoop, H., \& Nater, U. M. (2018). Hair and salivary cortisol in a cohort of women with chronic fatigue syndrome. Hormones and Behavior, 103, 1-6. https://doi.org/10.1016 /j.yhbeh.2018.05.016

Roos, K. L., \& Miravalle, A. (2014). Postinfectious encephalomyelitis. In W. M. Scheld, R. J. Whitley, \& C. M. Marra (Eds.), Infections of the central nervous system (4th ed., pp. 331-339). Philadelphia, PA: Wolters Kluwer Health.

Ropper, A., \& Samuels, M. (2009). Principles of neurology (9th ed.). New York, NY: McGraw Hill.

Sandroni, P. (2012). Clinical evaluation of autonomic disorders. In I. Biaggioni, G. Burnstock, P. A. Low, \& J. F. R. Paton (Eds.), primer on the autonomic nervous system (3rd ed., pp. 377382). Cambridge, MA: Academic Press.

Saper, C. B. (2002). The central autonomic nervous system: Conscious visceral perception and autonomic pattern generation. Annual Review of Neuroscience, 25, 433-469. https://doi.org/10.1146/annurev.neuro.25.032502.111311

Scheld, W. M., Whitley, R. J., \& Marra, C. M. (2014). Infections of the central nervous system (4th ed.). Philadelphia, PA: Lippincott Williams and Wilkins.

Schillings, M. L., Stegeman, D. F., \& Zwarts, M. J. (2005). Determining central activation failure and peripheral fatigue in the course of sustained maximal voluntary contractions: A model-based approach. Journal of Applied Physiology, 98(6), 2292-2297. https://doi.org/10.1152/japplphysiol.01342.2004

Sclocco, R., Kim, J., Garcia, R. G., Sheehan, J. D., Beissner, F., Bianchi, A. M., Cerutti, S., Kuo, B., Barbieri, R., \& Napadow, V. (2016). Brain circuitry supporting multi-organ autonomic outflow in response to nausea. Cerebral Cortex, 26(2), 485497. https://doi.org/10.1093/cercor/bhu172

Shan, Z. Y., Kwiatek, R., Burnet, R., Del Fante, P., Staines, D. R., Marshall-Gradisnik, S. M., \& Barnden, L. R. (2016). Progressive brain changes in patients with chronic fatigue syndrome: A longitudinal MRI study. Journal of Magnetic Resonance Imaging, 44(5), 1301-1311. https://doi.org /10.1002/jmri.25283

Sharma, Y., Xu, T., Graf, W. M., Fobbs, A., Sherwood, C. C., Hof, P. R., Allman, J. M., \& Manaye, K. F. (2010). Comparative anatomy of the locus coeruleus in humans and nonhuman primates. The Journal of Comparative Neurology, 518(7), 963-971. https://doi.org/10.1002/cne.22249

Shungu, D. C., Weiduschat, N., Murrough, J. W., Mao, X., Pillemer, S., Dyke, J. P., Medow, M. S., Natelson, B. H., Stewart, J. M., \& Mathew, S. J. (2012). Increased ventricular lactate in chronic fatigue syndrome. III. Relationships to cortical glutathione and clinical symptoms implicate oxidative stress in disorder pathophysiology. NMR in Biomedicine, 25(9), 1073-1087. https://doi.org/10.1002/nbm.2772

Siemionow, V., Fang, Y., Calabrese, L., Sahgal, V., \& Yue, G. H. (2004). Altered central nervous system signal during motor performance in chronic fatigue syndrome. Clinical Neurophysiology, 115(10), 2372-2381. https://doi.org /10.1016/j.clinph.2004.05.012

Snell, C. R., Stevens, S. R., Davenport, T. E., \& Van Ness, J. M. (2013). Discriminative validity of metabolic and workload measurements to identify individuals with chronic fatigue syndrome. Physical Therapy, 93(11), 1484-1492. https://doi.org/10.2522/ptj.20110368

Staud, R., Mokthech, M., Price, D. D., \& Robinson, M. E. (2015). Evidence for sensitized fatigue pathways in patients with chronic fatigue syndrome. PAIN, 156(4), 750-759. https://doi.org/10.1097/j.pain.0000000000000110

Stevens, S., Snell, C., Stevens, J., Keller, B., \& VanNess, J. M. (2018). Cardiopulmonary exercise test methodology for assessing exertion intolerance in myalgic encephalomyelitis/chronic fatigue syndrome. Frontiers in Pediatrics, 6, 242. https://doi.org/10.3389/fped.2018.00242

Tanaka, M., Tajima, S., Mizuno, K., Ishii, A., Konishi, Y., Miike, T., \& Watanabe, Y. (2015). Frontier studies on fatigue, autonomic nerve dysfunction, and sleep-rhythm disorder. The 
Journal of Physiological Sciences, 65(6), 483-498. https://doi.org/10.1007/s12576-015-0399-y

Tatsuoka, M. M., \& Lohnes, P. R. (1988). Multivariate analysis: Techniques for educational and psychological research, 2nd ed. New York, NY: Macmillan Publishing Co, Inc.

Togo, F., \& Natelson, B. H. (2013). Heart rate variability during sleep and subsequent sleepiness in patients with chronic fatigue syndrome. Autonomic Neuroscience, 176(1-2), 8590. https://doi.org/10.1016/j.autneu.2013.02.015

Topolovec, J. C., Gati, J. S., Menon, R. S., Shoemaker, J. K., \& Cechetto, D. F. (2004). Human cardiovascular and gustatory brainstem sites observed by functional magnetic resonance imaging. The Journal of Comparative Neurology, 471(4), 446-461. https://doi.org/10.1002/cne.20033

Toth, M., Faludi, B., Wackermann, J., Czopf, J., \& Kondakor, I. (2009). Characteristic changes in brain electrical activity due to chronic hypoxia in patients with obstructive sleep apnea syndrome (OSAS): A combined EEG study using LORETA and omega complexity. Brain Topography, 22(3), 185-190. https://doi.org/10.1007/s10548-009-0110-9

Turkeltaub, P. E., Eden, G. F., Jones, K. M., \& Zeffiro, T. A. (2002). Meta-analysis of the functional neuroanatomy of single-word reading: Method and validation. Neurolmage, 16(3, Part A), 765-780. https://doi.org/10.1006 /nimg.2002.1131

Underhill, R. A. (2015). Myalgic encephalomyelitis, chronic fatigue syndrome: An infectious disease. Medical Hypotheses, 85(6), 765-773. https://doi.org/10.1016/j.mehy.2015.10.011

Van Cauwenbergh, D., Nijs, J., Kos, D., Van Weijnen, L., Struyf, F., \& Meeus, M. (2014). Malfunctioning of the autonomic nervous system in patients with chronic fatigue syndrome: A systematic literature review. European Journal of Clinical Investigation, 44(5), 516-526. https://doi.org/10.1111 leci.12256

Van Den Eede, F., Moorkens, G., Van Houdenhove, B., Cosyns, P., \& Claes, S. J. (2007). Hypothalamic-pituitary-adrenal axis function in chronic fatigue syndrome. Neuropsychobiology, 55(2), 112-120. https://doi.org/10.1159/000104468

VanElzakker, M. B., Brumfield, S. A., \& Lara Mejia, P. S. (2018). Neuroinflammation and cytokines in myalgic encephalomyelitis/chronic fatigue syndrome (ME/CFS): A critical review of research methods. Frontiers in Neurology, 9, 1033. https://doi.org/10.3389/fneur.2018.01033

Vanness, M., Snell, C. R., \& Stevens, S. R. (2007). Diminished cardiopulmonary capacity during post-exertional malaise. Journal of Chronic Fatigue Syndrome, 14(2), 77-85. https://doi.org/10.1300/J092v14n02_07

Vanneste, S., \& De Ridder, D. (2013). Brain areas controlling heart rate variability in tinnitus and tinnitus-related distress. PLOS ONE, 8(3), e59728. https://doi.org/10.1371 /journal.pone.0059728

Vermeulen, R. C. W., \& Vermeulen van Eck, I. W. G. (2014). Decreased oxygen extraction during cardiopulmonary exercise test in patients with chronic fatigue syndrome.
Journal of Translational Medicine, 12, 20. https://doi.org/10.1186/1479-5876-12-20

Vitacco, D., Brandeis, D., Pascual-Marqui, R., \& Martin, E. (2002). Correspondence of event-related potential tomography and functional magnetic resonance imaging during language processing. Human Brain Mapping, 17(1), 4-12. https://doi.org/10.1002/hbm.10038

Ware, J. E., \& Sherbourne, C. D. (1992). The MOS 36-item shortform health survey (SF-36). I. Conceptual framework and item selection. Medical Care, 30(6), 473-483.

Ware, J. E., Kosinski, M., Bayliss, M. S., McHorney, C. A., Rogers, W. H., \& Raczek, A. (1995). Comparison of methods for the scoring and statistical analysis of SF-36 health profile and summary measures: Summary of results from the medical outcomes study. Medical Care, 33(4 Suppl.), AS264AS279.

Ware, J. E., Snow, K. K., Kosinski, M., \& Gandek, B. (1993). SF36 health survey: Manual and interpretation guide. Boston, MA: New England Medical Center, Health Institute.

Wyller, V. B., Eriksen, H. R., \& Malterud, K. (2009). Can sustained arousal explain the chronic fatigue syndrome? Behavioral Brain Functions, 5, 10. https://doi.org/10.1186/1744-9081-510

Yoshiuchi, K., Cook, D. B., Ohashi, K., Kumano, H., Kuboki, T., Yamamoto, Y., \& Natelson, B. H. (2007). A real-time assessment of the effect of exercise in chronic fatigue syndrome. Physiology \& Behavior, 92(5), 963-968. https://doi.org/10.1016/j.physbeh.2007.07.001

Zinn, M. A., Zinn, M. L., Valencia, I., Jason, L. A., \& Montoya, J. G. (2018). Cortical hypoactivation during resting EEG suggests central nervous system pathology in patients with chronic fatigue syndrome. Biological Psychology, 136, 87-99. https://doi.org/10.1016/j.biopsycho.2018.05.016

Zumsteg, D., Lozano, A. M., \& Wennberg, R. A. (2006a). Depth electrode recorded cerebral responses with deep brain stimulation of the anterior thalamus for epilepsy. Clinical Neurophysiology, 117(7), 1602-1609. https://doi.org/10.1016 /j.clinph.2006.04.008

Zumsteg, D., Lozano, A. M., Wieser, H. G., \& Wennberg, R. A. (2006b). Cortical activation with deep brain stimulation of the anterior thalamus for epilepsy. Clinical Neurophysiology, 117(1), 192-207. https://doi.org/10.1016/j.clinph.2005.09.015

Zumsteg, D., Wennberg, R. A., Treyer, V., Buck, A., \& Wieser, H. G. (2005). H2(15)O or $13 \mathrm{NH} 3$ PET and electromagnetic tomography (LORETA) during partial status epilepticus. Neurology, $\quad 65(10), \quad 1657-1660 . \quad$ https://doi.org/10.1212 101.wnl.0000184516.32369.1a

Zwarts, M. J., Bleijenberg, G., \& van Engelen, B. G. M. (2008). Clinical neurophysiology of fatigue. Clinical Neurophysiology, 119(1), 2-10. https://doi.org/10.1016/j.clinph.2007.09.126

Received: February 26, 2021

Accepted: April 8, 2021

Published: June 30, 2021 